\title{
Challenges and Successes in Raising a Child With Type 1 Diabetes and Autism Spectrum Disorder: Mixed Methods Study
}

Tamara K Oser ${ }^{1}$, MD; Sean M Oser ${ }^{1}$, MD, MPH; Jessica A Parascando ${ }^{2}$, MPH; Lee Ann Grisolano ${ }^{3}$, PhD; Kanthi Bangalore Krishna ${ }^{4}$, MD; Daniel E Hale ${ }^{4}$, MD; Michelle Litchman ${ }^{5}$, PhD, FNP-BC; Shideh Majidi ${ }^{6}$, MD; Paul Haidet ${ }^{7}$, $\mathrm{MD}, \mathrm{MPH}$

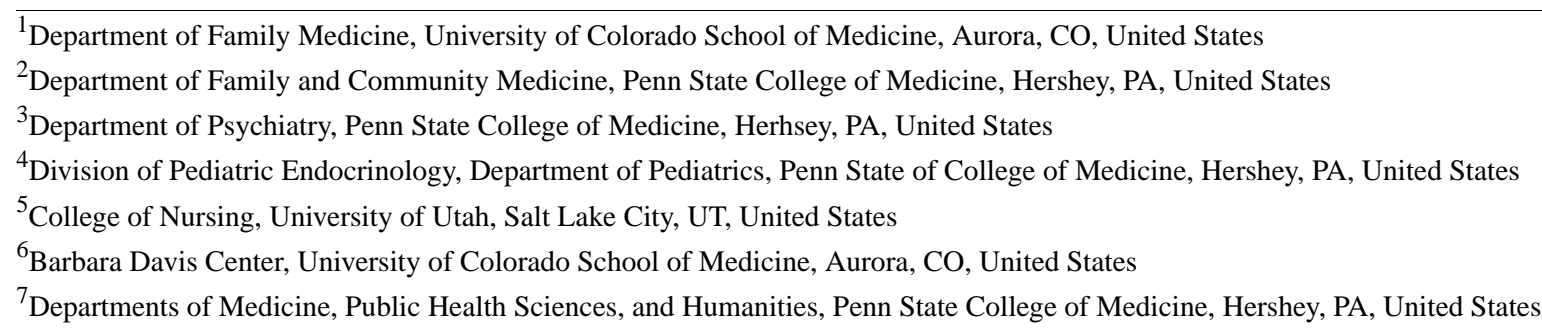

Corresponding Author:

Tamara K Oser, MD

Department of Family Medicine

University of Colorado School of Medicine

12631 East 17th Avenue, F496

Aurora, $\mathrm{CO}, 80045$

United States

Phone: 13037249700

Email: tamara.oser@cuanschutz.edu

\section{Abstract}

Background: Self-management of type 1 diabetes (T1D) requires numerous decisions and actions by people with T1D and their caregivers and poses many daily challenges. For those with T1D and a developmental disorder such as autism spectrum disorder (ASD), more complex challenges arise, though these remain largely unstudied.

Objective: This study aimed to better understand the barriers and facilitators of raising a child with T1D and ASD. Secondary analysis of web-based content (phase 1) and telephone interviews (phase 2) were conducted to further expand the existing knowledge on the challenges and successes faced by these families.

Methods: Phase 1 involved a qualitative analysis of publicly available online forums and blog posts by caregivers of children with both T1D and ASD. Themes from phase 1 were used to create an interview guide for further in-depth exploration via interviews. In phase 2, caregivers of children with both T1D and ASD were recruited from Penn State Health endocrinology clinics and through the web from social media posts to T1D-focused groups and sites. Interested respondents were directed to a secure web-based eligibility assessment. Information related to T1D and ASD diagnosis, contact information, and demographics were collected. On the basis of survey responses, participants were selected for a follow-up telephone interview and were asked to complete the adaptive behavior assessment system, third edition parent form to assess autism severity and upload a copy of their child's most recent hemoglobin $\mathrm{A}_{1 \mathrm{c}}\left(\mathrm{HbA}_{1 \mathrm{c}}\right)$ result. Interviews were transcribed, imported into NVivo qualitative data management software, and analyzed to determine common themes related to barriers and facilitators of raising a child with both ASD and T1D.

Results: For phase 1, 398 forum posts and blog posts between 2009 and 2016 were analyzed. Common themes related to a lack of understanding by the separate ASD and T1D caregiver communities, advice on coping techniques, rules and routines, and descriptions of the health care experience. For phase 2, 12 eligible respondents were interviewed. For interviewees, the average age of the child at diagnosis with T1D and ASD was 7.92 years and 5.55 years, respectively. Average self-reported and documented $\mathrm{HbA}_{1 \mathrm{c}}$ levels for children with T1D and ASD were $8.6 \%(70 \mathrm{mmol} / \mathrm{mol})$ and $8.7 \%(72 \mathrm{mmol} / \mathrm{mol})$, respectively. Common themes from the interviews related to increased emotional burden, frustration surrounding the amount of information they are expected to learn, and challenges in the school setting. 
Conclusions: Caregivers of children with both T1D and ASD face unique challenges, distinct from those faced by caregivers of individuals who have either disorder alone. Understanding these challenges may help health care providers in caring for this unique population. Referral to the diabetes online community may be a potential resource to supplement the care received by the medical community.

(J Med Internet Res 2020;22(6):e17184) doi: 10.2196/17184

\section{KEYWORDS}

type 1 diabetes; autism spectrum disorder; child; blogs; social media; qualitative research

\section{Introduction}

\section{Background}

Individuals with type 1 diabetes (T1D) spend over 8000 hours per year self-managing diabetes outside of the medical setting [1]. Optimal management includes numerous daily behaviors and decisions such as checking blood glucose levels, counting carbohydrates, calculating doses of and administering insulin, and changing dietary habits. Following this regimen is challenging for anyone, but for people with developmental disorders, such as autism spectrum disorder (ASD), this complex care can be even more demanding. Individuals with ASD can have impairments in social communication and interaction as well as repetitive or restrictive behaviors and preferences [2]. Behaviors and activities that individuals with ASD perceive as unimportant or do not understand, such as self-care, health and safety awareness, and activities of daily living, can be very difficult for them to manage independently, which can make the complexity of self-managing diabetes even more challenging. In addition, over $30 \%$ of people with ASD also have an intellectual disability (ID), which can add additional challenges in the self-management of T1D [3].

T1D prevalence is increasing, affecting 1.25 million people in the United States in 2014, and 5 million people are expected to be affected by 2050 [4-6]. Up to 1 in 59 children in the United States have been identified with ASD [7], and the reported prevalence of ASD is also increasing [3,7]. There is little research regarding the prevalence of individuals with both ASD and T1D in the United States [3,6-8], although a recent study found the prevalence of ASD in the pediatric T1D population in 1 clinic to be $1.16 \%$ (95\% CI 0.96-1.26) [9]. An additional study reported that among 10,032 participants from the T1D Exchange Clinic Network, 159 (1.58\%) had T1D and ASD [10]. These studies suggest that there is no increased prevalence of ASD in children with diabetes. However, research has documented that people with ID alone may be more likely to develop T1D as a result of having genetic conditions such as Down syndrome $[11,12]$. In addition, $31 \%$ of children with ASD also have an ID [3]. Although ASD alone may not lead to increased diabetic ketoacidosis, severe hypoglycemia, or worsening glycemic control [10], T1D patients with both ASD and comorbid ID are more likely to have very poor glycemic control, higher emergency room utilization, and lower rates of achieving national standards of diabetes management, including lower rates of lipid screening and retinopathy screening [11-13]. With this comes greater risk for negative outcomes, and indeed diabetes-related morbidity and mortality have been identified as a particular concern for people with ID [14,15]. As people with ASD and ID live longer, it has become even more important that they achieve better long-term disease management, including glycemic control and control of other modifiable risk factors, to decrease the occurrence of potentially preventable complications as they age. The interplay between ASD with or without ID and impacts on clinical, behavioral, and psychosocial outcomes related to T1D continue to be areas where little has been explored. Many factors may be involved in such interplay and outcomes, including access to social support and social networks [16], which may be valuable resources in raising a child with both T1D and autism.

Although there have been great advances over the last decades in health care delivered to children with chronic conditions, not all children have benefited equally [17]. Although there is a well-developed evidence base regarding diabetes care and education for populations without ASD or ID, very little research has been done to better understand optimal ways to deliver education and behavioral interventions and to align clinical care with the needs of families raising a child with both T1D and ASD, with or without an ID.

\section{Objectives}

This study sought to better understand self-management challenges and successes experienced by families with experience in raising a child with both T1D and ASD to lay the groundwork for future studies. This will enable the exploration of interventions to improve diabetes outcomes and reduce health disparities in this special population and other unique populations of children living with diabetes and other chronic medical conditions. To the best of our knowledge, this is the first study that utilizes a qualitative component to allow further exploration of the lived experience of raising a child with both T1D and ASD. We also sought to gather some exploratory information on glycemic control related to the degree of adaptive function in light of the coexisting ASD, hypothesizing that adaptive impairment may be associated with hemoglobin $A_{1 c}$ $\left(\mathrm{HbA}_{1 \mathrm{c}}\right)$.

\section{Methods}

\section{Design and Ethics}

This study involved an innovative approach consisting of 2 phases and included the use of social media as well as traditional interviews to capitalize on the strengths of each. In the first phase, secondary data analysis of web-based content was conducted to understand the challenges and successes families raising a child with T1D and ASD experience, similar to our other studies using web-based content to evaluate barriers and 
facilitators of living with or raising a child with T1D $[18,19]$. The themes generated from this study were used to create an interview guide that was used in phase 2 to interview caregivers of children with varying degrees of glycemic control and ASD severity to provide richer exploration of the lived experience in raising a child with both T1D and ASD. This 2-step approach allowed further exploration of initial themes identified from the secondary data analysis of web-based content, with the advantage of being able to ask follow-up questions.

This study was approved by the Penn State College of Medicine institutional review board through expedited review and was considered to be no greater than minimal risk. No procedures or participant interactions took place before receiving this approval.

\section{Phase 1}

\section{Recruitment}

No individuals were actively recruited for the first phase of the study, as it consisted of a secondary data analysis of publicly available data. Content from a publicly available forum and 2 blogs were identified through an internet search using the search terms type 1 diabetes and autism and diabetes and autism, which would capture both autism and autism spectrum disorder.

\section{Analysis}

Qualitative methods are appropriate for generating new knowledge and hypotheses, especially when little is known about the area of investigation [20]. This type of analysis allows the emergence of themes from the data when there are no existing hypotheses to test, such as in this understudied population of children living with both T1D and ASD.

A total of 2 experienced qualitative researchers (TO and SO) undertook data analysis. Content from online forums and blogs were imported into NVivo version 12 qualitative software (QSR International Pty Ltd) post by post. After reviewing blogs and forum posts and noting initial impressions, a codebook was developed and revised through ongoing discussions among the study team. To establish Cohen $\kappa$ (a measure of interrater reliability in qualitative coding) [21], the primary coders (TO and SO) each coded $20 \%$ of the dataset $(\kappa=0.996)$. With the established interrater reliability, the remaining posts and blog comments in the full dataset were coded. The research team employed an exploratory inductive thematic approach to construct emergent themes [22]. Themes from the analysis of web-based content were used to create an interview guide for use in the second phase of the study.

\section{Phase 2}

\section{Recruitment}

For the second phase of the study, participants were recruited on the web, through physician referral, and with flyers posted in the waiting room of an academic pediatric endocrinology practice. Participants were considered eligible if they were a caregiver (parent, grandparent, adult sibling, or guardian) to a child aged 5-18 years with both T1D and ASD; able to read, write, and communicate effectively in English; and had telephone and internet access. A summary explanation of the research was provided, including implied consent upon reading the summary of explanation and agreeing to participate.

\section{Instrument}

The eligibility survey was hosted in Research Electronic Data Capture (REDCap), a secure electronic data collection system [23]. The survey was tested for technological function before distribution, and questions were answered on 1 page. REDCap automatically captures the date of survey completion and completeness of the survey and assigns each participant a unique study code number. Participants were unable to go back in the survey and change their answers. The survey could only be completed once per Internet Protocol address. Participants reported demographics and information related to their child's conditions and diabetes provider.

\section{Interview}

Survey participants were also asked if they would consent to a subsequent 30-min telephone interview. The interview guide was developed based on the thematic qualitative analysis of web-based content in phase 1 . This included themes that seemed fully or nearly fully contextualized by the web-based data as well as themes that may not have been as fully developed, as the phase 2 interviews were used to assess the potential completeness of the phase 1 themes as well as to elicit deeper and more nuanced exploration of the phase 1 themes. To do this, a random sample of interview participants from online recruitment sources was selected for interviews based on consent and responses to the survey questions. As certain demographic groups (eg, clinic patients) were underrepresented in this sample, we also purposively chose to interview the few clinic patients who completed the survey $(n=2)$. Such a targeted, purposive approach to adding participants is standard in qualitative research, as it is 1 of the distinct features that increases efficiency and yield, thereby minimizing overrepresentation and unneeded effort from participants in groups adequately represented [24]. This strategy enabled an interview sample large enough to reach saturation in the interviews, as is also typical of such qualitative research [24].

Telephone interviews were scheduled based on the earliest convenience of the participant. The interviews lasted approximately $30 \mathrm{~min}$ and were conducted by 3 authors $(\mathrm{PH}$, $\mathrm{SO}$, and TO). Interviews were audio recorded on a hand-held device and then transferred to a secure web-based storage location with access limited to the study team and an approved Health Insurance Portability and Accountability Act (HIPAA)-compliant transcriptionist.

After scheduling the interview, participants received a link to the adaptive behavior assessment system, third edition (ABAS-3) parent form [25], also hosted in REDCap, and were instructed to complete it either before or after the telephone interview. The ABAS-3 parent form assesses the functional skills of children and adolescents who display various types of limitations, disabilities, or disorders, much like those subjectively displayed by children with ASD and ID. The items included assess everyday activities required, eg, to function adaptively, respond to environmental demands, care for oneself, and interact with others. The results of the ABAS-3 identify, 
among other things, strengths and limitations as well as the need for services and support $[25,26]$. The general adaptive composite (GAC) scores were derived from all of the adaptive skills areas in the assessment and ranged from 40 to 120 . Higher scores indicate a greater level of daily functioning, whereas lower scores suggest impairments in any of a variety of adaptive areas that are assessed by the ABAS-3. The further the GAC score deviates downward from what is considered typical of an individual's age, the greater the impairment in function. For example, a GAC score of 65 would suggest a greater level of impairment in adaptive behavior than a GAC score of 95 .

Participants were also asked to upload a copy of the child's most recent $\mathrm{HbA}_{1 \mathrm{c}}$ result (within the past 4 months) into the REDCap survey. After completing all procedures, participants were compensated for their time and effort with a gift card.

\section{Analysis}

In all, 12 respondents were interviewed. Interviews were transcribed using HIPAA-compliant Penn State transcription services. Interview transcripts were imported into NVivo 12
(QSR International) for analysis and analyzed as detailed above through an exploratory inductive thematic qualitative approach (Cohen $\kappa$ after $20 \%=0.942$ ). Attempts were made to include caregivers of children with varying degrees of glycemic control and varying degrees of function related to their ASD.

Descriptive statistics were calculated for ABAS-3 parent form data and for $\mathrm{HbA}_{1 \mathrm{c}}$ results were also calculated by subgroups based on $\mathrm{HbA}_{1 \mathrm{c}}$ being $<7.5 \%(<58 \mathrm{mmol} / \mathrm{mol})$ or $\geq 7.5 \%(\geq 58$ $\mathrm{mmol} / \mathrm{mol}$ ) according to then-current American Diabetes Association glycemic target recommendations [27].

\section{Results}

\section{Phase 1}

There were 398 posts between 2009 and 2016 from a publicly available forum for caregivers raising a child with both T1D and ASD (117 unique members) and 25 individual blog posts from 2 blogs authored by a caregiver to a child with T1D and ASD. In all, 4 themes emerged from phase 1 (Table 1). 
Table 1. Phase 1 themes and representative quotes from analysis of online forums and blogs.

\begin{tabular}{lll}
\hline Themes & Representative web-based quotes \\
\hline $\begin{array}{l}\text { Parents of children with T1D and } \\
\text { autism yearned for support and did } \\
\text { not feel understood by the autism } \\
\text { community or the T1D community; }\end{array}$ & $\begin{array}{c}\text { "I feel left out of the T1D groups because Aspergers brings a whole new set of concerns. But the Aspie } \\
\text { groups are completely afraid of T1D." }\end{array}$ \\
$\begin{array}{l}\text { "Like you said - the autism community is not equipped for our extra needs and the diabetes community } \\
\text { just doesn't get the autism side of it." }\end{array}$ \\
$\begin{array}{l}\text { peer support from families that un- } \\
\text { derstood the unique experience of } \\
\text { raising a child with both conditions. }\end{array}$ \\
$\begin{array}{ll}\text { know what this is like." } \\
\text { "I am so thrilled to have found this group! I knew there were other families like ours but I didn't know } \\
\text { how/where to access them. I am in tears right now because I feel so overwhelmed knowing that there are } \\
\text { other people who understand the everyday trials (and victories!) both autism and diabetes bring to your } \\
\text { life } 24 / 7 . "\end{array}$
\end{tabular}

Numerous coping techniques were discussed, including focusing on T1D management first, as glucose levels could affect behavior.

Descriptions of the health care experience, including the helpfulness of multidisciplinary teams with endocrinologists and autism specialists jointly developing treatment plans.

- "What has worked is focusing on diabetes management first. When his blood sugars are high he is so irritable and easily set off."

- "We chose to focus on T1D first because I do believe that has a huge effect on his behavior."

- "But the Endocrinologists I've encountered don't seem to see it that way. Ours acts like autism and diabetes are as related as a sprained ankle + appendicitis. To them, diabetes is about numbers and autism doesn't affect those. (Ha!)"

- $\quad$ "Psychiatrists have only a passing familiarity with insulin dependence from an hour or two during med school, and they are mostly only interested in how it intersects with the meds they prescribe. So again, you as the advocate have to navigate the separate systems, trying to educate whoever is willing to listen along the way."

- "My suggestion would be that the Endo consult with your regular doctor. A treatment and medical management plan should be put into place between the two offices. You may also ask for nutritionist, OT and behavior consults to help your child learn more about his diabetes and how his anger issues play into his blood glucose levels."

Sensory issues precluding the use of technology such as insulin pumps and the utility of tubeless pumps in overcoming some of these challenges.
- "My son is on shots, BTW. We tried a pump for a brief time but he wouldn't tolerate it. He pulled it off up to three times a day."

- "We went with the tubeless pump for the reasons that have come up...we were concerned about our son messing with the controls and we also knew that for a kid with sensory issues, the external tubing would be a real problem."

- "There was NO WAY my son could have dealt with tubing, but he's not having problems with the tubeless pump, we've been very pleased."

- "There is just no way my sensory son would have tolerated tubing so I am glad we pursued the tubeless pump option."

- "The one thing that helped with sensory issues for things attached [insulin pump, CGM] was I started putting bandaids on for everything-- every shot, bump, bruise, etc. After a few years he hardly noticed them...and as long as the tubing is tucked in he won't use that as something to self-stimulate with."
${ }^{\mathrm{a} T 1 D}$ : type 1 diabetes.

\section{Phase 2}

In phase 2, 12 participants were selected for a telephone interview from among 29 respondents who completed the eligibility survey. Information related to participant demographics and study variables such as $\mathrm{HbA}_{1 \mathrm{c}}$ and ABAS-3 parent form scores were obtained (Table 2). On average, both interview participants and the broader group of survey respondents were similar in current age, age of child's diagnosis with T1D, age of child's diagnosis with ASD, and self-reported $\mathrm{HbA}_{1 \mathrm{c}}$. For both interview participants and survey respondents, the majority reported that they were white, not Hispanic or Latino, lived in a suburban setting, and visited their child's provider every 3-6 months. The majority of both groups reported using continuous glucose monitoring (CGM). The majority of survey respondents reported using an insulin pump, whereas interview participants were evenly split.

In the study sample, 8 individuals had the most recent $\mathrm{HbA}_{1 \mathrm{c}}$ $>7.5 \%$, with an average of $9.7 \%$ (SD 1.89), or $82.5 \mathrm{mmol} / \mathrm{mol}$ (SD 20.5); 4 individuals had the most recent $\mathrm{HbA}_{1 \mathrm{c}}<7.5 \%$, averaging $6.9 \%$ (SD 0.29), or $52.8 \mathrm{mmol} / \mathrm{mol}$ (SD 2.9). There was no statistically significant difference in GAC scores between those with $\mathrm{HbA}_{1 \mathrm{c}}>7.5 \%$ (mean 68.6, SD 14.22) and those with $\mathrm{HbA}_{1 \mathrm{c}}<7.5 \%$ (mean 76.3, SD 11.73; $\mathrm{t}_{10}=0.92 ; P=.38$ ).

Overall, 3 themes emerged from an inductive thematic analysis of content obtained from interviews during phase 2 (Table 3 ). 
Table 2. Phase 2 participant characteristics.

\begin{tabular}{|c|c|c|}
\hline Variable & Interview participants $(n=12)$ & Survey respondents (not interviewed; $n=17$ ) \\
\hline Child's current age (years), mean (SD) & $12.3(3.1)$ & $12.6(3.7)$ \\
\hline Child's age at diagnosis with T1D ${ }^{\mathrm{a}}$ (years), mean (SD) & $7.9(2.8)$ & $7.3(3.4)$ \\
\hline Child's age at diagnosis with $\mathrm{ASD}^{\mathrm{b}}$ (years), mean (SD) & $5.6(3.5)$ & $5.6(3.8)$ \\
\hline Self-reported $\mathrm{HbA}_{1 \mathrm{c}}{ }^{\mathrm{c}}, \%(\mathrm{mmol} / \mathrm{mol})$ & $8.6(70)$ & $7.7(61)$ \\
\hline Laboratory confirmed $\mathrm{HbA}_{1 \mathrm{c}}, \%(\mathrm{mmol} / \mathrm{mol})$ & $8.7(72)$ & $\mathrm{N} / \mathrm{A}^{\mathrm{d}}$ \\
\hline \multicolumn{3}{|l|}{ Country of residence, $\mathrm{n}(\%)$} \\
\hline United States & $12(100)$ & $17(100)$ \\
\hline \multicolumn{3}{|l|}{ Gender, n (\%) } \\
\hline Female & $5(42)$ & $7(41)$ \\
\hline \multicolumn{3}{|l|}{ Race, $\mathbf{n}(\%)$} \\
\hline White & $11(92)$ & $16(94)$ \\
\hline Black & $0(0)$ & $1(6)$ \\
\hline More than 1 race & $1(8)$ & $0(0)$ \\
\hline \multicolumn{3}{|l|}{ Ethnicity, n (\%) } \\
\hline Hispanic or Latino & $1(8)$ & $0(0)$ \\
\hline Not Hispanic or Latino & $11(92)$ & $16(94)$ \\
\hline Unknown/not reported & $0(0)$ & $1(6)$ \\
\hline \multicolumn{3}{|l|}{ Setting, n (\%) } \\
\hline Urban & $2(17)$ & $4(23)$ \\
\hline Rural & $0(0)$ & $3(18)$ \\
\hline \multicolumn{3}{|l|}{ CGM $^{\mathrm{e}}$ use, n (\%) } \\
\hline Yes & $8(67)$ & $13(77)$ \\
\hline No & $4(33)$ & $4(23)$ \\
\hline \multicolumn{3}{|l|}{ Insulin pump use, n (\%) } \\
\hline Yes & $6(50)$ & $14(82)$ \\
\hline No & $6(50)$ & $3(18)$ \\
\hline Tubeless pump use among subset of pump users, n (\%) & $5(83)$ & $7(50)$ \\
\hline \multicolumn{3}{|l|}{ Distance to provider, n (\%) } \\
\hline 0-10 miles & $3(25)$ & $4(23)$ \\
\hline 11-20 miles & $2(17)$ & $3(18)$ \\
\hline $21-50$ miles & $7(58)$ & $6(35)$ \\
\hline$>50$ miles & $0(0)$ & $4(23)$ \\
\hline \multicolumn{3}{|c|}{ Frequency of provider visits (usual care is every 3 months), $n$ (\%) } \\
\hline$<3$ months & $1(8)$ & $0(0)$ \\
\hline 3-6 months & $11(927)$ & $16(94)$ \\
\hline$>6$ months & $0(0)$ & $1(6)$ \\
\hline ABAS $-3^{\mathrm{f}}$ GAC ${ }^{\mathrm{g}}$ standard score, mean $(95 \% \mathrm{CI})$ & $71.2(67.9-74.4)$ & N/A \\
\hline
\end{tabular}

${ }^{\mathrm{a}} \mathrm{T} 1 \mathrm{D}$ : type 1 diabetes.

${ }^{\mathrm{b}}$ ASD: autism spectrum disorder. 
${ }^{\mathrm{c}} \mathrm{HbA}_{1 \mathrm{c}}$ : hemoglobin $\mathrm{A}_{1 \mathrm{c}}$.

${ }^{\mathrm{d}} \mathrm{N} / \mathrm{A}$ : not applicable.

${ }^{\mathrm{e}} \mathrm{CGM}$ : continuous glucose monitoring.

${ }^{\mathrm{f}} \mathrm{ABAS}-3$ : adaptive behavior assessment system, third edition.

${ }^{\mathrm{g}} \mathrm{GAC}$ : general adaptive composite.

Table 3. Phase 2 themes and representative quotes from analysis of interviews.

\begin{tabular}{l}
\hline Theme \\
$\begin{array}{l}\text { Caregivers of children with T1D a and } \\
\text { autism face emotional burdens that may be } \\
\text { more than additive compared with raising }\end{array}$ \\
$\begin{array}{l}\text { a child with only T1D or autism, and they } \\
\text { describe the constant monitoring and work }\end{array}$ \\
required to care for their children.
\end{tabular}

Caregivers of children with T1D and autism express frustration surrounding the amount of T1D information they are expected to learn and the manner in which it is presented.

Caregivers describe numerous challenges surrounding their child's experience in the school setting.
"Sometimes people should understand that the best learning is from somebody teaching you and not from reading it."

- One caregiver describes a nurse educator who told her "you should know how to do this already. Just change the insulin. You should know how to do that already," and her concern "that's a really dangerous statement to make to a parent who's new, who you never taught to change those doses."

- "They showed me how to put it [the CGM] in and sent me on my merry way, which was the hardest thing ever to learn. I had to then put it in on my own and it took me three tries and I ruined two sensors. I felt so bad because I didn't know how to do it."

- Another caregiver described how a health care provider "handed me the Pink Panther [reference book regarding type 1 diabetes] and thought I had read it all."

- "I feel like especially with the hurdles we deal with, a lot more education from the onset would be very helpful."

- Caregivers offered solutions such as "make step by step videos like the "how to' videos seen on YouTube" and offering "extra appointments and longer appointments."

- "I am literally on call even when she's at school. Even though she has an aide and there's a nurse, they will still call me to come help take care of her on a daily basis."

- "They've dealt with her eloping from the classroom for years and they know she's a good hider. They knew about the diabetes. I mean, I know they're only human, but my goodness. If you lose a diabetic autistic child, that's kind of a big deal."

- "I stepped down from my position as a paralegal to take care of my child and I now work at my daughter's school, just to make sure that she is ok."

- Multiple caregivers described how they had to take "time off", "reduce to part-time," or even "take jobs at the school to be available to assist with [their] child's care".

- "Schools are not doing the best they can to help these kids. Sometimes they think the kids can do it on their own where you know they have more challenges and they need more help."

- "No one can work together to get us what we need."
T1D: type 1 diabetes.

\section{Discussion}

\section{Principal Findings}

Caregivers raising a child with comorbid T1D and ASD face unique challenges that are not well understood by families with a child with only 1 of the individual conditions or by health care providers, as evident by the themes that emerged from phase 1. Themes were generally related to the combination of T1D and ASD and focused on coping techniques, advice on needles and technology, health care experience, and sensory issues related to technology (eg, insulin pumps). Themes from phase 2 are complementary. Although some could be interpreted as applying to nearly anyone performing T1D management (with or without coexisting ASD), many of the diabetes-specific challenges were influenced (and generally amplified) by the coexistence of ASD.

To the best of our knowledge, this is the first study with a large qualitative component to better understand the experience of raising a child with both T1D and ASD. The use of both social media and interviews as qualitative data sources in this special population provided a deeper understanding than using either type of data source alone, much like we found in another study using social media and interviews in a sample of adults with T1D [18]. 
Overall, our study results show that children who have greater impairment in function based on adaptive skills areas do not achieve target $\mathrm{HbA}_{1 \mathrm{c}}$ values. On the basis of the themes that emerged from our interviews (phase 2), this may be due to the additional barriers that come with the comorbidity, overwhelming amount of information to learn, and challenges in the school setting. More detailed comparisons around our exploratory aim were not conclusive due to the small sample size, not surprisingly.

Caregivers who shared the many challenges they face in raising a child with T1D and ASD might benefit from expanded social networks to provide social support, including emotional, instrumental, informational, and appraisal support. Both in-person support and referral to components of the online caregiver community specific to comorbid T1D and ASD could be valuable resources, as supportive ties may enhance well-being and health of the caregivers, which has been shown to lead to positive outcomes in children with T1D [28-34]. Social networks can provide much needed emotional support, exemplified by 1 participant who, upon finding such a web-based resource, "WEPT tears of joy that there are other parents out there who know what this is like." Instrumental support might result if caregivers to a child with comorbid T1D and ASD find they are geographically able to provide assistance such as babysitting services, because finding caregivers for any child with T1D presents challenges, and these challenges may be significantly increased in a child with both T1D and ASD [19]. This study shows that caregivers identified numerous coping techniques, including focusing on T1D management first, establishing concrete rules and routines, advice on types of needles and technology, and suggestions for health care appointments. Prioritizing disease-specific tasks when diabetes coexists with other health conditions has been reported elsewhere [35]. Referral to social networks where this kind of informational support can be shared may be highly valuable. Appraisal support in the form of feedback may be especially useful to caregivers with a child newly diagnosed with either T1D or ASD in the setting of having previously been diagnosed with the other condition, as receiving feedback that the challenges they are facing are real and being handled to the best of the caregiver's ability may help the caregiver in coping with the added new diagnosis.

A modified conceptual model for the relationship of social networks and social support to health can be applied to this unique population (Figure 1, adapted from Glanz et al [16]). Pathway 1 shows that through the expansion of social networks, the supportive ties developed may enhance caregiver health and well-being, which is linked in multiple studies to improved diabetes outcomes in their youth. Pathway 2 represents the hypothesized effect of social networks and social support on individuals' coping resources. By being able to access new contacts and information to help solve the unique challenges faced by families raising a child with T1D and ASD, there may be a sense or perception of increased control that may also improve the physical and mental health of caregivers. The community of health care providers caring for these children should consider referral to web-based caregiver sites specific for families raising children with both T1D and ASD. By providing resources to these families to strengthen their social networks, the community of health care providers caring for these children may also feel more empowered in caring for this challenging population, as shown in pathway 4 . Pathways $2 \mathrm{a}$ and 4a demonstrate the buffering effect, whereby the negative effects of the stressful experience of raising a child with T1D and ASD described in this study may be diminished through an expanded social network and having health care providers who understand the potential role of peer support in coping. Pathway 3 illustrates how receiving information through an expanded social network may reduce the amount of stress experienced, which, in turn, can lead to improved mental and physical health in caregivers of children with T1D and ASD. Finally, pathway 5 describes the potential effects of social networks and support on health behaviors. By exchanging information and support, caregivers to a child with T1D and ASD may be more supported in health behaviors that improve the care of their child and themselves as well. 
Figure 1. A modified conceptual model for the relationship of social networks and social support to health, specific to type 1 diabetes and autism spectrum disorder. ASD: autism spectrum disorder; HCP: health care practitioner; T1D: type 1 diabetes.

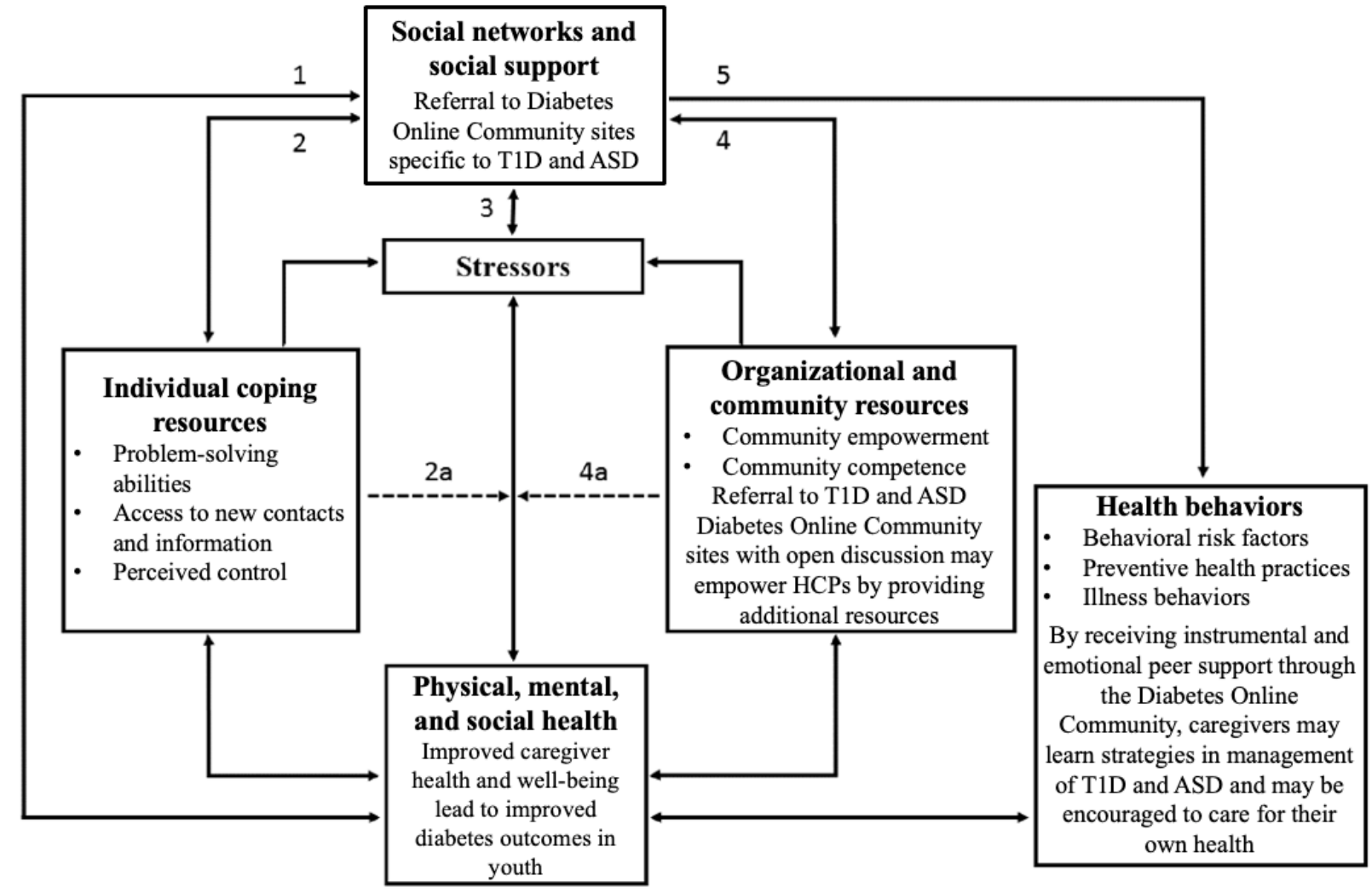

\section{Comparison With Previous Work}

Our study demonstrated that the majority of survey respondents $(8 / 12,67 \%)$ and interview participants $(13 / 17,77 \%)$ had a child who used CGM technology. However, $82 \%$ (14/17) of the survey respondents reported their child using an insulin pump, compared with only 50\% (6/12) of interview participants. Among those using insulin pumps, the majority use tubeless pumps $(12 / 20,60 \%$ overall, $5 / 6,83 \%$ of interviewees and $7 / 14$, $50 \%$ of survey respondents).

These findings complement the work of Stanek et al [9] and Bethin et al [10], who found that CGM use was the same among children with T1D and ASD as it was among those with T1D but without ASD, whereas insulin pump use was lower for those with both T1D and ASD. This qualitative work adds some explanatory context, as caregivers identified that sensory issues can preclude the successful use of insulin pumps and that successful solutions for some have included the use of tubeless pumps and desensitization techniques, such as the routine use of band-aids before attempting to use diabetes technology.

$\mathrm{HbA}_{1 \mathrm{c}}$ among study participants was not statistically correlated with the degree of function related to ASD, but it was limited by sample size. However, the trends of 2 comparisons (mean GAC scores of those achieving target $\mathrm{HbA}_{1 \mathrm{c}}$ vs those not achieving target $\mathrm{HbA}_{1 \mathrm{c}}$ and correlation of GAC scores with $\mathrm{HbA}_{1 \mathrm{c}}$ ) were both in the direction that one would expect: children who scored higher in skills of daily living had improved $\mathrm{HbA}_{1 \mathrm{c}}$ values $(<7.5 \%)$. It is not surprising that this study did not achieve statistical significance, as it was not powered to do so and the sample size was chosen for the greater qualitative focus here. This also echoes comments by Bethin et al [10] and Stanek et al [9] that further work is needed to be able to better support these children and their families. From this study specifically, we propose that further research with larger sample sizes is needed to continue to explore the potential relationships between the degree of functioning related to ASD and glycemic control.

\section{Limitations}

Limitations of this study include the lack of representation of caregivers from diverse ethnic backgrounds and rural areas. In addition, although attempts were made to recruit both from an endocrinology clinic and the diabetes online community (DOC), a minority of participants were recruited through the clinic. An additional limitation is that the search strategy included autism to capture ASDs but did not specifically include Asperger and may, therefore, have limited the scope of search returns. However, this would not fully exclude representation of Asperger's-related content as it is an ASD, and it would also tend to skew the sample toward more severe levels of impairment, increasing the ability to identify challenges within the sample. This study aligns with previous work involving the DOC that demonstrates a larger web presence of white individuals living in suburban or urban areas, which is not likely representative of the greater population with comorbid T1D and ASD [36]. This may represent a health disparity whereby those in rural areas or from diverse ethnic backgrounds may not be aware of the DOC, may not have access, or may not feel welcome or included in that space. 


\section{Conclusions}

Raising a child with both ASD and T1D presents significant self-management challenges. However, caregivers of this population identify various coping techniques and strategies and find support in social media sites specific to this unique population. Further research is needed to develop new ways for the health care community to partner with this population.

\section{Acknowledgments}

This research was funded by the Penn State College of Medicine Qualitative Research Initiative. The authors would like to thank the caregivers of children with T1D and ASD for their participation in this study. The authors would also like to thank Dr Cheryl Tierney for reviewing the interview guide and Jessica Wright for contributing to study start-up and project management.

\section{Conflicts of Interest}

None declared.

\section{References}

1. Hilliard ME, Sparling KM, Hitchcock J, Oser TK, Hood KK. The emerging diabetes online community. Curr Diabetes Rev 2015;11(4):261-272 [FREE Full text] [doi: 10.2174/1573399811666150421123448] [Medline: 25901500]

2. American Psychiatric Association. Diagnostic and Statistical Manual of Mental Disorders (DSM-5). Washington, DC, USA: American Psychiatric Association; 2013.

3. Baio J, Wiggins L, Christensen DL, Maenner MJ, Daniels J, Warren Z, et al. Prevalence of autism spectrum disorder among children aged 8 years-autism and developmental disabilities monitoring network, 11 sites, United States, 2014. MMWR Surveill Summ 2018 Apr 27;67(6):1-23 [FREE Full text] [doi: 10.15585/mmwr.ss6706a1] [Medline: 29701730]

4. Centers of Disease Control and Prevention. 2014. National Diabetes Statistics Report: Estimates of Diabetes and Its Burden in the United States URL: https://stacks.cdc.gov/view/cdc/23442/cdc 23442 DS1.pdf? [accessed 2020-04-21]

5. Imperatore G, Boyle JP, Thompson TJ, Case D, Dabelea D, Hamman RF, SEARCH for Diabetes in Youth Study Group. Projections of type 1 and type 2 diabetes burden in the US population aged <20 years through 2050: dynamic modeling of incidence, mortality, and population growth. Diabetes Care 2012 Dec;35(12):2515-2520 [FREE Full text] [doi: 10.2337/dc12-0669] [Medline: 23173134]

6. Dabelea D, Mayer-Davis EJ, Saydah S, Imperatore G, Linder B, Divers J, SEARCH for Diabetes in Youth Study. Prevalence of type 1 and type 2 diabetes among children and adolescents from 2001 to 2009. J Am Med Assoc 2014 May 7;311(17):1778-1786 [FREE Full text] [doi: 10.1001/jama.2014.3201] [Medline: 24794371]

7. Centers for Disease Control and Prevention. 2019. Data \& Statistics on Autism Spectrum Disorder URL: http://www. cdc.gov/ncbddd/autism/data.html [accessed 2015-06-30]

8. Xu G, Strathearn L, Liu B, Bao W. Prevalence of autism spectrum disorder among US children and adolescents, $2014-2016$. J Am Med Assoc 2018 Jan 2;319(1):81-82 [FREE Full text] [doi: 10.1001/jama.2017.17812] [Medline: 29297068]

9. Stanek KR, Youngkin EM, Pyle LL, Raymond JK, Driscoll KA, Majidi S. Prevalence, characteristics, and diabetes management in children with comorbid autism spectrum disorder and type 1 diabetes. Pediatr Diabetes 2019 Aug;20(5):645-651. [doi: 10.1111/pedi.12848] [Medline: 30912248]

10. Bethin KE, Kanapka LG, Laffel LM, Majidi S, Chaytor NS, MacLeish S, T1D Exchange Clinic Network. Autism spectrum disorder in children with type 1 diabetes. Diabet Med 2019 Oct;36(10):1282-1286. [doi: 10.1111/dme.14069] [Medline: 31271682]

11. Taggart L, Coates V, Truesdale-Kennedy M. Management and quality indicators of diabetes mellitus in people with intellectual disabilities. J Intellect Disabil Res 2013 Dec;57(12):1152-1163. [doi: 10.1111/j.1365-2788.2012.01633.x] [Medline: 23106688]

12. Anwar AJ, Walker JD, Frier BM. Type 1 diabetes mellitus and Down's syndrome: prevalence, management and diabetic complications. Diabet Med 1998 Feb;15(2):160-163. [doi: 10.1002/(SICI)1096-9136(199802)15:2<160::AID-DIA537>3.0.CO;2-J] [Medline: 9507919]

13. Shireman TI, Reichard A, Nazir N, Backes JM, Greiner KA. Quality of diabetes care for adults with developmental disabilities. Disabil Health J 2010 Jul;3(3):179-185. [doi: 10.1016/j.dhjo.2009.10.004] [Medline: 21122783]

14. Janicki MP, Dalton AJ, Henderson CM, Davidson PW. Mortality and morbidity among older adults with intellectual disability: health services considerations. Disabil Rehabil 1999;21(5-6):284-294. [doi: 10.1080/096382899297710] [Medline: $\underline{10381241]}$

15. Rey-Conde T, Lennox N. Delivering diabetes care to people with intellectual disability. Diabetes Voice 2007;52(2):16-18 [FREE Full text]

16. Glanz K, Rimer BK, Viswanath K. Health Behavior and Health Education: Theory, Research, and Practice. Hoboken, New Jersey: John Wiley \& Sons; 2008.

17. Berry JG, Bloom S, Foley S, Palfrey JS. Health inequity in children and youth with chronic health conditions. Pediatrics 2010 Dec;126(Suppl 3):S111-S119. [doi: 10.1542/peds.2010-1466D] [Medline: 21123473] 
18. Oser TK, Minnehan KA, Wong G, Parascando J, McGinley E, Radico J, et al. Using social media to broaden understanding of the barriers and facilitators to exercise in adults with type 1 diabetes. J Diabetes Sci Technol 2019 May;13(3):457-465 [FREE Full text] [doi: 10.1177/1932296819835787] [Medline: $\underline{\text { 30862185] }}$

19. Oser TK, Oser SM, McGinley EL, Stuckey HL. A novel approach to identifying barriers and facilitators in raising a child with type 1 diabetes: qualitative analysis of caregiver blogs. JMIR Diabetes 2017 Oct 26;2(2):e27 [FREE Full text] [doi: 10.2196/diabetes.8966] [Medline: 30291073]

20. Sandelowski M. Using qualitative research. Qual Health Res 2004 Dec;14(10):1366-1386. [doi: 10.1177/1049732304269672] [Medline: 15538005$]$

21. Cohen J. A coefficient of agreement for nominal scales. Educ Psychol Meas 1960 Jul 2;20(1):37-46. [doi: 10.1177/001316446002000104]

22. Nowell LS, Norris JM, White DE, Moules NJ. Thematic analysis: striving to meet the trustworthiness criteria. Int J Qual Methods 2017 Oct 2;16(1):-. [doi: 10.1177/1609406917733847]

23. Harris PA, Taylor R, Thielke R, Payne J, Gonzalez N, Conde JG. Research electronic data capture (REDCap)-a metadata-driven methodology and workflow process for providing translational research informatics support. J Biomed Inform 2009 Apr;42(2):377-381 [FREE Full text] [doi: 10.1016/j.jbi.2008.08.010] [Medline: 18929686]

24. Creswell JW, Creswell JD. Research Design: Qualitative, Quantitative, and Mixed Methods Approaches. Thousand Oaks, California: Sage Publications; 2017.

25. Harrison P, Oakland T. Pearson Assessments. 2015. Adaptive Behavior Assessment System URL: https://www. pearsonassessments.com/store/usassessments/en/Store/Professional-Assessments/Behavior/Brief/ Adaptive-Behavior-Assessment-System-\%7C-Third-Edition/p/100001262.html [accessed 2020-04-21]

26. Harrison PL, Oakland T. Adaptive behavior assessment system. In: Kreutzer J, DeLuca J, Caplan B, editors. Encyclopedia of Clinical Neuropsychology. New York, USA: Springer; 2017:1-4.

27. American Diabetes Association. Children and adolescents: standards of medical care in diabetes-2019. Diabetes Care 2019 Jan;42(Suppl 1):S148-S164. [doi: 10.2337/dc19-S013] [Medline: 30559239]

28. Berkman L, Glass T. Social integration, social networks, social support, and health. Soc Epidemiol 2000;1:137-173 [FREE Full text] [doi: 10.4135/9781412952576.n192]

29. Berkman LF, Glass T, Brissette I, Seeman TE. From social integration to health: Durkheim in the new millennium. Soc Sci Med 2000 Sep;51(6):843-857. [doi: 10.1016/s0277-9536(00)00065-4] [Medline: 10972429]

30. Clayton KM, Stewart SM, Wiebe DJ, McConnel CE, Hughes CW, White PC. Maternal depressive symptoms predict adolescent healthcare utilization and charges in youth with type 1 diabetes (T1D). Health Psychol 2013 Sep;32(9):1013-1022. [doi: 10.1037/a0032761] [Medline: 24001252]

31. Dale JR, Williams SM, Bowyer V. What is the effect of peer support on diabetes outcomes in adults? A systematic review. Diabet Med 2012 Nov;29(11):1361-1377. [doi: 10.1111/j.1464-5491.2012.03749.x] [Medline: 22804713]

32. Eckshtain D, Ellis DA, Kolmodin K, Naar-King S. The effects of parental depression and parenting practices on depressive symptoms and metabolic control in urban youth with insulin dependent diabetes. J Pediatr Psychol 2010 May;35(4):426-435 [FREE Full text] [doi: 10.1093/jpepsy/jsp068] [Medline: 19710249]

33. Cunningham NR, Vesco AT, Dolan LM, Hood KK. From caregiver psychological distress to adolescent glycemic control: the mediating role of perceived burden around diabetes management. J Pediatr Psychol 2011 Mar;36(2):196-205 [FREE Full text] [doi: 10.1093/jpepsy/jsq071] [Medline: 20736389]

34. Maas-van Schaaijk NM, Roeleveld-Versteegh AB, van Baar AL. The interrelationships among paternal and maternal parenting stress, metabolic control, and depressive symptoms in adolescents with type 1 diabetes mellitus. J Pediatr Psychol 2013;38(1):30-40. [doi: 10.1093/jpepsy/jss096] [Medline: 22988060]

35. Litchman ML, Allen NA, McAdam-Marx C, Feehan M. Using projective exercises to identify patient perspectives of living with comorbid type 2 diabetes and asthma. Chronic Illn 2019 Sep 7:- epub ahead of print. [doi: 10.1177/1742395319872788] [Medline: $\underline{31495200]}$

36. Litchman ML, Walker HR, Ng AH, Wawrzynski SE, Oser SM, Greenwood DA, et al. State of the science: a scoping review and gap analysis of diabetes online communities. J Diabetes Sci Technol 2019 May;13(3):466-492 [FREE Full text] [doi: 10.1177/1932296819831042] [Medline: 30854884]

\section{Abbreviations}

ABAS-3: adaptive behavior assessment system, third edition

ASD: autism spectrum disorder

CGM: continuous glucose monitoring

DOC: diabetes online community

GAC: general adaptive composite

HbA $_{1 c}$ : hemoglobin $A_{1 c}$

HIPAA: Health Insurance Portability and Accountability Act

ID: intellectual disability 
REDCap: Research Electronic Data Capture

T1D: type 1 diabetes

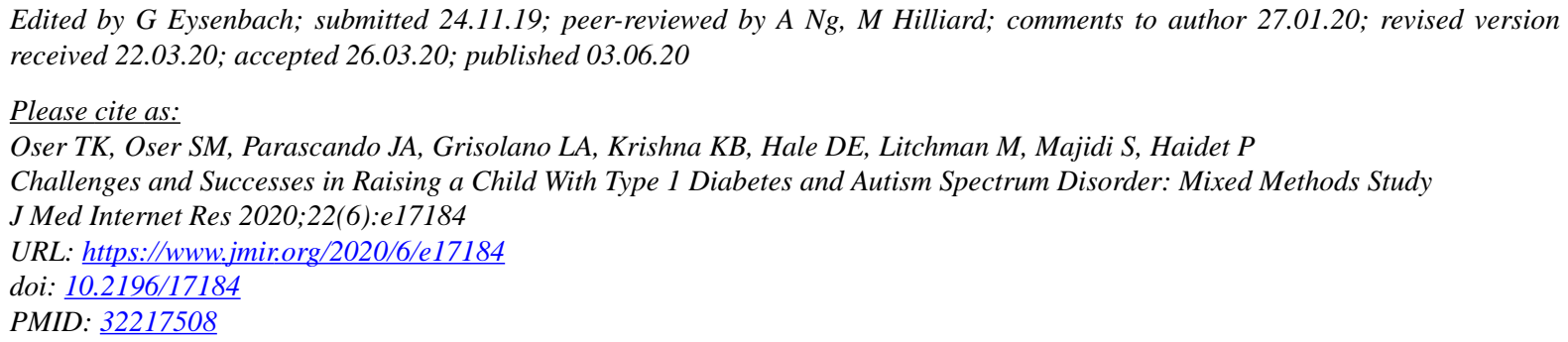

(CTamara K Oser, Sean M Oser, Jessica A Parascando, Lee Ann Grisolano, Kanthi Bangalore Krishna, Daniel E Hale, Michelle Litchman, Shideh Majidi, Paul Haidet. Originally published in the Journal of Medical Internet Research (http://www.jmir.org), 03.06.2020. This is an open-access article distributed under the terms of the Creative Commons Attribution License (https://creativecommons.org/licenses/by/4.0/), which permits unrestricted use, distribution, and reproduction in any medium, provided the original work, first published in the Journal of Medical Internet Research, is properly cited. The complete bibliographic information, a link to the original publication on http://www.jmir.org/, as well as this copyright and license information must be included. 